\title{
Olhar da gestão sobre a implantação da ficha de notificação da violência doméstica, sexual e/outras violências em uma metrópole do Brasil The management's view about the implementation of the form for the notification of domestic, sexual and other types of violence in a Brazilian metropolis
}

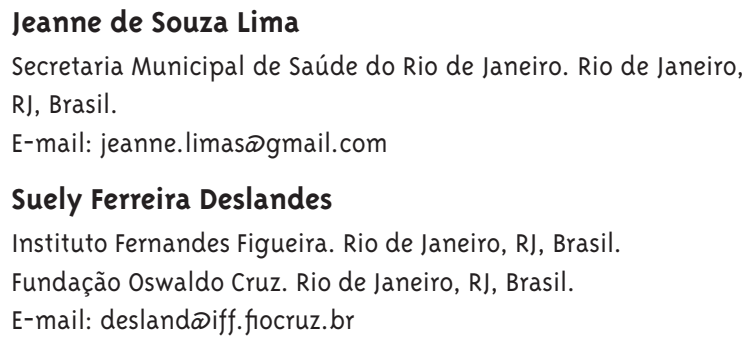

Secretaria Municipal de Saúde do Rio de Janeiro. Rio de Janeiro, RJ, Brasil.

E-mail: jeanne.limas®gmail.com

\section{Suely Ferreira Deslandes}

Instituto Fernandes Figueira. Rio de Janeiro, RJ, Brasil.

Fundação Oswaldo Cruz. Rio de Janeiro, RJ, Brasil.

E-mail: deslandळiff.fiocruz.br

\section{Resumo}

O artigo apresenta um estudo exploratório sobre o processo de implantação da ficha de notificação da violência doméstica, sexual e/ou outras violências contra crianças e adolescentes. 0 campo de estudo foi o município do Rio de Janeiro. Trata-se de uma pesquisa de natureza qualitativa que utilizou as técnicas de entrevista com gestores/técnicos do nível central e de grupo focal com representantes das coordenações de áreas de planejamento. Verificou-se que apesar de a Secretaria Municipal de Saúde do Rio Janeiro ser pioneira na institucionalização da notificação de maus-tratos, a descontinuidade das ações para o enfrentamento da violência ainda é uma realidade. No que tange à notificação, a gestão em saúde nos diferentes níveis hierárquicos ainda enfrenta vários obstáculos relacionados à incorporação permanente do tema da violência na agenda da política pública de saúde, ainda que demarcando o esforço das ações voltadas para a capacitação dos profissionais de saúde e a interlocução e a articulação com a rede intra e intersetorial.

Palavras-chave: Violência; Notificação; Vigilância em Saúde; Crianças e Adolescentes.

\section{Correspondência}

Jeanne de Souza Lima

Av. Afonso Cavalanti, 455, sala 80I, Cidade Nova.

Rio de Janeiro, RJ, Brasil. CEP 202॥-॥I. 


\section{Abstract}

The article presents an exploratory study about the process of implementation of the notification form of domestic, sexual and/or other types of violence against children and adolescents. The field of study was the city of Rio de Janeiro. This qualitative research used the techniques of interview with central level managers/technicians and focus group with representatives of the coordination of programmatic areas. It was found that, although the Municipal Health Department of Rio Janeiro is a pioneer in the institutionalization of the notification of maltreatment, the discontinuity of actions for addressing violence is still a reality. Concerning notification, the health management at different hierarchical levels still faces several obstacles related to the permanent incorporation of the theme of violence in the agenda of the public health policy, even if we take into account the effort of actions targeted at the qualification of health professionals and the dialogue and articulation with the intra- and inter-sector network.

Keywords: Violence; Notification; Health Surveillance; Children and Adolescents.

\section{Introdução}

A violência nos últimos 30 anos vem se destacando entre as principais causas de morbimortalidade em todo o mundo (OMS, 2002). Com a mudança do perfil epidemiológico, observa-se a incorporação de doenças e agravos não transmissíveis ao escopo de atividades da vigilância epidemiológica (Veloso et al., 2013; Minayo, 2006). As violências contra crianças e adolescentes são reconhecidas como violação dos direitos humanos e um grave problema de saúde pública (OMS, 2002) por suas implicações imediatas e futuras para a saúde física e emocional das vítimas, consequências negativas para o desenvolvimento cognitivo, afetivo e social, pela possibilidade de replicação do fenômeno em futuras gerações e pela alta incidência ainda que subnotificada (Habigzang et al., 2008; OMS, 2002).

A experiência dos EUA em notificar casos de violência contra crianças e adolescentes, desde 1970, é reconhecida como uma iniciativa estatal pioneira em regular ações públicas para o enfrentamento da violência intrafamiliar (Finkelhor, 1979). Todos os estados americanos possuem leis e políticas que especificam os procedimentos para notificação compulsória de casos suspeitos de violência contra crianças e profissionais envolvidos na notificação. Os padrões para se fazer uma notificação podem variar de estado para estado, bem como as informações coletadas (Lima; Deslandes, 2011; US, 2009; US, 2008a).

No Brasil, a partir da segunda metade dos anos de 1980, a notificação começou a preocupar defensores de direitos humanos e trabalhadores na área de atenção à criança e ao adolescente. O Estatuto da Criança e do Adolescente (ECA), em 1990, prevê que casos suspeitos ou confirmados de maus tratos contra crianças e adolescentes sejam comunicados ao Conselho Tutelar (CT). O Estatuto define, ainda, que médico e professor ou responsável por estabelecimento de saúde e de ensino são obrigados a realizar esta comunicação e estão sujeitos a multa pela omissão (Brasil, 2004b).

Com sentido técnico específico para a Saúde, a notificação é a comunicação da ocorrência de determinada doença ou agravo, feita à autoridade sanitária por profissionais de saúde ou cidadão, para fins de adoção das medidas de intervenção 
pertinentes. Destina-se, em primeira instância, ao serviço local incumbido de controlar a ocorrência. Quando reunidas de forma sistematizada, as notificações passam a compor sistemas de informações próprios que possibilitam o acompanhamento das características do fenômeno estudado, sua distribuição e tendências. A notificação compulsória (NC) é realizada nas situações nas quais a norma legal obriga os profissionais de saúde e pessoas da comunidade a comunicar à autoridade sanitária a ocorrência de doenças ou agravos que estão sob vigilância epidemiológica (Teixeira et al., 1998). Dessa maneira a NC tem sido a principal fonte de informação da vigilância epidemiológica. Para a inclusão da violência no rol das doenças e agravos de NC, foram considerados a magnitude, a transcendência, a vulnerabilidade, os compromissos internacionais e nacionais e o Regulamento Sanitário Internacional (Patrício; Michaloski; Rujula, 2011).

Nos casos de violência contra crianças e adolescentes, a notificação realizada no campo da Saúde tem dois propósitos diferentes e complementares. A principal finalidade é de desencadear ações de proteção e medidas que visem cessar a violência. A segunda finalidade, no contexto da vigilância epidemiológica, é dimensionar o problema, indicando a demanda por ações de intervenção, permitindo o monitoramento, a análise de possíveis mudanças no perfil desses agravos e o planejamento de ações intersetoriais de prevenção, além de subsidiar pesquisas (Assis et al., 2012; Gonçalves; Ferreira, 2002).

Observa-se que várias iniciativas foram adotadas pelo Ministério da Saúde (MS) em função da consolidação de um sistema de informação voltado para as situações de violência. Em 2001 o MS institucionalizou através de Portaria a notificação de casos de suspeita ou de confirmação de maus tratos contra crianças e adolescentes atendidos no Sistema Único de Saúde (SUS) (Brasil, 2001b, 2002). Esta portaria apoiava-se também na Política Nacional Redução da Morbimortalidade por Acidentes e Violências (PNRMAV), em sua diretriz sobre a monitorização da ocorrência de violências e acidentes. Uma das medidas é a adoção de um registro padronizado das informações, de modo a possibilitar a elaboração de pesquisas e estratégias de intervenção voltadas, especificamente, para o enfrentamento da violência contra crianças e adolescentes, a partir dos quais viabilizar-se-ia a retroalimentação do sistema, contribuindo, assim, para a melhoria do atendimento prestado a estes segmentos (Brasil, 2001a).

Visando dar continuidade às ações governamentais no que se refere à informação, o MS implantou em 2006, o Sistema de Vigilância de Violências e Acidentes (VIVA). O Viva é constituído por dois componentes:1) Viva/Sinan, que é formado pela vigilância contínua de violência doméstica, sexual, e/ou outras violências interpessoais e autoprovocadas, e 2) Viva Inquérito, sob a modalidade de inquérito sobre violências e acidentes em serviços sentinelas de urgência e emergência de municípios selecionados. Essas duas modalidades de vigilância possuem sistemas de informação próprios, que permitem a entrada e a análise dos dados obtidos por meio de duas fichas distintas: Viva/Sinan: Ficha de Notificação/Investigação Individual de Violência Doméstica, Sexual e/ou outras Violências; Viva Inquérito: Ficha de Notificação de Violências e Acidentes em Unidades de Urgência e Emergência (Brasil, 2013).

A utilização de uma ficha de notificação de violência padronizada para todo o território brasileiro, fundamental a um sistema de informação, é muito recente em nosso país e muito pouco se conhece das estratégias regionais adotadas para implantação do referido instrumento. Neste sentido, o presente artigo apresenta uma descrição e análise do processo de implantação da ficha de notificação/investigação da violência doméstica, sexual e/ou outras violências pela Secretaria Municipal de Saúde do Rio de Janeiro SMS/RJ, a partir da ótica de seus gestores. Tal perspectiva permite incorporar o confronto entre os quadros normativos que regem a implantação de um sistema de vigilância e a ação intersubjetiva dos sujeitos, seus modos de fazer, calcados em certa cultura institucional e circunscritos numa dada lógica organizacional (L'Abbate, 2003).

Análises que visam a compreensão do processo de implantação têm como foco a relação entre a intervenção (políticas, programas, serviços, ações) e seu contexto de inserção na produção de efeitos. A compreensão das diversas injunções de natureza técnica, ética ou política, relacionadas ao sucesso ou resistência organizacional se tornam indispensáveis de serem analisadas no momento de se 
explicar - o porquê e o como - da efetividade das ações específicas para o enfrentamento da violência (Hartz; Silva, 2005).

Adotamos a perspectiva da sociologia interpretativa hermenêutica quanto à primazia da ação dos agentes e dos significados atribuídos por eles para o reconhecimento da racionalidade de uma dada prática social. Esta perspectiva foi reconduzida a partir da vertente crítica, percebendo que a consciência histórica dos agentes sociais não se constrói externa à experiência (Bleicher, 1980).

\section{Metodologia}

Trata-se de uma pesquisa de natureza qualitativa, de cunho exploratório, centrada nos esquemas interpretativos de compreensão de dinâmicas interacionais, reconhecendo a questão do significado e da intencionalidade como inerentes aos atos, às relações e às estruturas sociais (Minayo, 2008; Víctora; Knauth; Hassen, 200o).

O Município do Rio de Janeiro foi o campo escolhido desta pesquisa por investir na implantação da ficha de notificação preconizada pelo MS a partir de 2009; contar com gestores e técnicos da SMS/RJ que desenvolveram ações pioneiras de intervenção em maus tratos/abuso sexual, tais como a instituição de uma ficha de notificação em 1996, para ser utilizada por toda a rede de saúde; por ser uma das capitais com maior contingente populacional do país, possuindo uma rede vasta e complexa de atenção à saúde que permite identificar, notificar, atender e acompanhar casos de crianças e adolescentes que sofreram abuso sexual.

Os sujeitos investigados foram todos os gestores e/ou técnicos do nível central da SMS/RJ e técnicos representantes das Coordenações de Áreas de Planejamento (CAP) responsáveis pela implantação da ficha de notificação nas unidades de saúde. Foram realizadas sete entrevistas semiestruturadas com gestores/técnicos do nível central (Superintendência de Promoção da Saúde, Superintendência de Vigilância em Saúde/Gerência de Informação Epidemiológica, Superintendência de Hospitais Pediátricos e Maternidades, Gerências da Criança, Adolescente e Mulher). Os gestores/técnicos do nível central foram identificados pela letra $\mathrm{G}$ numerada de
1 a 7 e todos foram considerados do sexo masculino no intuito de preservar suas identidades.

O município do Rio de Janeiro é dividido em dez Coordenações de Áreas de Planejamento (CAP 1.o, 2.1, 2.2, 3.1, 3.2, 3.3, 4.0, 5.1, 5.2, 5.3) com diferentes características demográficas. No sentido de agregar os diferentes níveis de planejamento das políticas públicas de saúde, foi realizado um grupo focal com representantes das CAPs 3.1, 3.2 e 3.3, eleitas por representarem conjuntamente o território com maior contingente populacional (2.399.159 habitantes) (Instituto Pereira Passos, 2011) e maior número de registro de notificação de violência sexual. 0 grupo focal contou com a participação de sete profissionais de saúde (um médico, três assistentes sociais e três enfermeiros) cuja heterogeneidade permite incluir distintas visões e experiências. A sessão durou cerca de duas horas.

Foi realizada adicionalmente uma entrevista grupal com dois profissionais da CAP 5.1 (um assistente social e um enfermeiro). Esta CAP foi eleita por representar uma das áreas com menor número de registro de notificação de abuso sexual, permitindo analisar a experiência com prováveis obstáculos à implantação da ficha. A duração da entrevista foi de 33 minutos.

Documentos da SMS/RJ sobre o tema foram consultados, constituindo acervo complementar. 0 trabalho de campo transcorreu nos meses de janeiro, fevereiro e março de 2011.

A análise abrangeu as seguintes fases: préanálise, exploração do material, tratamento dos resultados e interpretação (Gomes, 1994). A primeira fase configurou-se como a leitura flutuante do material, onde foram definidos, principalmente, as unidades de registro, unidade de contexto, trechos significativos e identificados nos temas e subtemas das categorias definidas no projeto (categorias analíticas). Na segunda fase, os dados foram ordenados e realizou-se a leitura exaustiva do material para a construção de um mapa onde se organizaram os temas e subtemas segundo cada corpus (gestores/ técnicos e representantes das CAPs). Na terceira, buscou-se desvendar o conteúdo subjacente ao que foi manifesto, sendo identificadas as regularidades e singularidades das falas.

Os roteiros de entrevistas adotados para todos 
os sujeitos incluíram os mesmos temas. 0 acervo se organizou a partir dos temas de interesse do estudo e foram analisados os sentidos atribuídos pelos sujeitos (Gomes, 1994) acerca das: condições e práticas anteriores à implantação da ficha Sinan; contexto, práticas e obstáculos vigentes para a notificação do abuso sexual contra crianças e adolescentes.

Organizou-se o material a partir do seguinte plano analítico: num primeiro nível o resgate da experiência anterior, seus modos de operar e a constituição de um fluxo da informação. Num segundo nível, foi feita a caracterização dos contextos político e operacional de implantação da ficha Sinan. Buscou-se articular estes dois níveis de forma transversal, dialogando a experiência dos atores e seus contextos institucionais.

A pesquisa foi aprovada pelo Comitê de Ética em Pesquisa da SMS/RJ em 27/o9/10 sob o parecer n. 252/2010 e protocolo de pesquisa n. 145/10.

\section{Resultados e discussão}

\section{Ações para a notificação de maus tratos contra crianças e adolescentes anteriores à ficha Sinan}

Os entrevistados resgataram a memória institucional das iniciativas de notificação. Lembraram que a SMS/RJ implantou uma ficha de notificação compulsória em 1996, através das gerências técnicas de saúde da criança e do adolescente, instituindo um fluxo de atuação em parceria com os CT. O planejamento e implantação das ações voltadas para a notificação e o enfrentamento da violência contaram com a parceria de organizações não governamentais, universidade, sociedade de pediatria e o Instituto de Puericultura e Pediatria Martagão Gesteira.

Outra estratégia apontada foi a criação do Grupo de Trabalho (GT) de Violência coordenado pela Gerência do Adolescente. Esta experiência é invocada pelos profissionais da rede de forma positiva, ainda que possuindo abrangência limitada.

Acho que de 2002 a 2004, 2005, era esse GT que era bem interessante. Era uma vez por mês e todo mês era uma discussão de um tema um pouco diferente. Isso era interessante, porque meio que atualizava os profissionais. (Entrevistados CAP 5.1)
A cartilha Protegendo nossas Crianças e Adolescentes, de 1996, foi apontada como um recurso para prevenção da violência doméstica junto às crianças, aos adolescentes e suas famílias. Pudemos verificar que esta cartilha foi reimpressa pelo MS em 2008, demonstrando o pioneirismo do município na prevenção e no enfrentamento deste fenômeno.

Foi mencionado que naquele momento, apesar das iniciativas das gerências, havia dificuldades em garantir a participação de médicos nos seminários e capacitações. Segundo depoimentos, a notificação ficava centrada em um único profissional de saúde, as assistentes sociais.

A presença do médico foi posteriormente ampliada entre 2004 e 2006 nas ações de capacitação para adotar a Norma Técnica Prevenção e Tratamento dos Agravos Resultantes da Violência Sexual contra Mulheres e Adolescentes (Brasil, 2012). Objetivavam divulgar o fluxo de atendimento e as unidades de referências de abuso sexual; os serviços oferecidos, agilizar o acesso das vítimas de violência sexual à profilaxia das Doenças Sexualmente Transmissíveis - DST/Aids; o acompanhamento previsto nas situações de violência e o seguimento nos serviços de saúde pelo período de seis meses. Todavia, naquela ocasião a questão da notificação não fora enfatizada nas sensibilizações.

Em 2004 veio o protocolo de atendimento a vítima de violência sexual para a capacitação dos profissionais no atendimento... ai já era específico sobre a questão da violência sexual. Nesse período, que eu acho que durou um ano e meio, teve um investimento. Aí sim, teve essa coisa de se buscar outros profissionais, em todas as maternidades, nos centros de saúde, para atender os homens e meninos. (...) Depois disso ficou um bom tempo sem nada. (Entrevistados CAP 5.1)

Infere-se que as sensibilizações se fizeram em função de um momento oportuno, em um contexto favorável, mas também oscilante, tanto em termos de visibilidade do problema da violência como de interesse na agenda pública municipal. Este interesse foi pactuado entre atores envolvidos, em especial as organizações não governamentais de militância dos direitos da criança, do adolescente e da mulher. 
Nesse sentido, as ações voltadas para a sensibilização mostraram-se assistemáticas. Os entrevistados constataram que nos períodos próximos às capacitações sobre a temática, as notificações aumentavam, dado confirmado pela literatura (Assis et al., 2012; Galdino; Santana; Ferrite, 2012).

Ficou, o que... três anos sem ter nada de novo. Assim, a coisa ia meio que se perdendo. Se percebe que quando não tinha muito investimento, as notificações ficavam cada vez mais escassas. (Entrevistados CAP 5.1)

\section{o fluxo anterior ao Sinan}

Os depoimentos indicaram que a orientação à época em relação à ficha anterior ao Sinan era de que a notificação fosse realizada em três vias. Uma via permanecia na unidade notificadora, em geral arquivada no Serviço Social e/ou direção, a segunda seguia para o CT de referência de moradia da criança/adolescente e, a outra era enviada para o nível central, para a gerência de saúde da criança ou do adolescente. As CAPs naquele momento não foram implicadas no fluxo. Os maiores notificadores eram ligados à rede hospitalar e os casos mais notificados eram os agudos da violência. Naquele momento não existia a estratégia de saúde da família implantada na rede.

Os dados eram sistematizados sem grande sofisticação, armazenados em uma planilha $\varepsilon x$ cell. Até 2006 não era atribuição da vigilância em saúde a organização dos dados produzidos a partir da notificação, ficando sob a responsabilidade dos programas.

Foi informado que o banco continha apenas informações de identificação tais como: unidade de atendimento; área programática da unidade notificante, profissionais envolvidos; idade, sexo e cor da vítima; caracterização do tipo de maus tratos e provável autor das agressões. Os dados qualitativos e descritivos desta ficha não eram sistematizados.

Havia o acúmulo de fichas não digitadas por falta de recursos humanos e operacionais, como a falta ou incompatibilidade de computadores. Isto repercutia na ausência de divulgação dos dados e do retorno de informações para a rede de saúde. Quando possível, os dados eram divulgados nas oficinas de capacitação sobre a temática e na supervisão junto às equipes de saúde.

Como apontado por estudiosos do tema, a ausência de ações de controle por parte da gestão, os quais frequentemente descuidam de dar retorno aos notificantes, dos resultados das análises realizadas e das ações que foram desencadeadas corroboram também para o descrédito dos propósitos da notificação por parte dos profissionais de saúde (Teixeira et al., 1998).

\section{Contexto, condições, práticas e obstáculos: as ações para implantação da ficha de notificação Sinan}

\section{Contexto de implantação da ficha}

Segundo depoimentos, em 2008 a Vigilância em Saúde do MS inicia as aproximações com a Superintendência de Vigilância em Saúde (SVS) do município para testar a ficha Sinan. Com a mudança de governo municipal em 2009, as pactuações entre as gerências técnicas e as superintendências foram (re) feitas e a violência não somente passou a ser uma das prioridades na vigilância em saúde, mas sua incorporação alavancou o setor.

Foi muito bom para vigilância, porque não existia uma gerência de VIGDANT IVigilância de Doenças e Agravos Não Transmissíveis] [...]aí a gente ganha mais espaço de recursos, na estrutura. (Entrevistado $\mathrm{G}_{3}$ )

Segundo depoimentos representantes da SMS/ RJ e a área técnica de Vigilância de Acidentes e Violências do MS, em abril de 2009, planejaram a mobilização para a adesão de toda a rede municipal de saúde à ficha Sinan. No decorrer do primeiro semestre do referido ano, as discussões foram amadurecidas no nível central entre técnicos das gerências da criança, adolescente, mulher e idoso, além da superintendência de promoção da saúde, saúde do trabalhador, saúde da família e saúde mental. Foi um momento valioso para planejar as ações voltadas para a notificação da violência ocorrida em todos os ciclos de vida. Todavia o Rio de Janeiro em meados de 2009 viveu a epidemia da H1N1 e as discussões e os trabalhos foram interrompidos. 
A ideia era de fazer em setembro (seminário), mas não foi possível na época por questão de recursos, pela questão da gripe, a história da epidemia, o Rio parou [...], não tinha clima para se falar do tema. (Entrevistado G3)

As interrupções no processo de trabalho acarretaram desestruturação das ações. Isto se configura em um efeito cascata que se inicia no nível central, repercute nas CAPs e consequentemente, nas unidades de saúde. Nesse sentido, continuaram sendo muito escassos os recursos (financeiros, de gestão, humanos e culturais) investidos na elaboração de respostas adequadas para o enfrentamento da violência dentro do setor de Saúde ou em colaboração com outros setores sociais.

Em outubro de 2009, foi regulamentado o Núcleo de Promoção da Solidariedade e Prevenção das Violências (NPSPV), ligado à Superintendência de Promoção da Saúde (SPS), como uma instância coordenadora e promotora de ações colegiadas e intersetoriais, no âmbito das ações da SMS/RJ. Dentre as suas diversas competências, estava incluída a implantação da ficha de notificação Sinan.

\section{Sensibilizações e capacitações para a implantação da ficha Sinan}

O período que compreendeu os últimos meses de 2009 e o ano de 2010 marcou uma crescente atuação da SMS/RJ em promover capacitações para a utilização da ficha e para o estabelecimento de seu fluxo. Além do apoio do MS, as parcerias com a Secretaria de Estado de Saúde do Rio de Janeiro, através da Área de Técnica de Ações contra a Violência (ATAV), e o Centro Latino de Estudos da Violência (Claves) da Fundação Oswaldo Cruz, revelando a compreensão da vigilância em violência como um processo que exige articulação intersetorial.

Em 2009 foi realizado o Seminário Municipal de Promoção da Solidariedade e Prevenção das Violências - implantando a ficha de notificação da violência doméstica, sexual e outras violências no Sinan Net envolvendo 198 profissionais de saúde e outros parceiros estratégicos na rede de enfrentamento da violência.

Entre novembro 2009 e março de 2010, foram realizadas oficinas descentralizadas nas 10 áreas de planejamento para implantação da referida ficha, vista como um instrumento de proteção às pessoas em situação de violência e um dispositivo da linha de cuidado (Brasil, 2010). As oficinas totalizaram 268 participantes e os profissionais de saúde da família participaram massivamente, pois esta foi a estratégia adotada para mobilizar os profissionais da atenção básica.

Em setembro de 2010, foi realizada a I Mostra da Vigilância de Doenças e Agravos Não Transmissíveis com a apresentação de trabalhos ligados ao tema da violência, envolvendo 120 profissionais. Os dados coletados, até então, a partir da nova ficha de notificação da violência, foram apresentados.

No período de julho a dezembro de 2010, foram realizados encontros regionais nas 10 áreas de planejamento, contando com a participação de 403 profissionais e outros pertencentes às secretarias municipais de Saúde, Educação e Assistência Social. Em algumas coordenações de área de planejamento participaram, ainda, representantes do CT, de ONGs, do Conselho Distrital de Saúde, entre outros.

\section{o fluxo da ficha de notificação Sinan}

De acordo com a Linha de Cuidado para Atenção Integral à Saúde de Crianças, Adolescentes e suas Famílias em Situação de Violências (Brasil, 2010), a ficha de notificação deve ser preenchida em três vias: a original deve ser encaminhada ao Serviço de Vigilância Epidemiológica, da Secretaria de Saúde do Município; a segunda via deve ser encaminhada ao CT e/ou autoridades competentes (Vara da Infância e Juventude ou Ministério Público); e a terceira via fica na Unidade de Saúde que notificou o caso de violência.

Vale destacar, ainda, que os municípios têm autonomia para adequar o fluxo da notificação dos casos suspeitos ou confirmados de violência doméstica, sexual e outras violências às suas necessidades. Assim, segundo os entrevistados, a SMS/RJ definiu o seu próprio fluxo: (1) a unidade deve manter uma cópia da ficha no prontuário/boletim de atendimento do paciente; (2) no caso de criança e adolescente, deve-se notificar ao CT, encaminhando outra cópia da ficha; (3) as unidades de saúde encaminham a ficha original para a CAP de sua área de referência aos cuidados do grupo articulador; (4) a original segue para o nível central, especificamente para a Coordenação de Análise e Situação de Saúde da 
Secretaria de Vigilância de Saúde do Rio de Janeiro SVS/RJ, para digitação e transferência eletrônica de dados para Secretaria de Estado de Saúde.

A expectativa é de que o grupo articulador atue no sentido de supervisionar os casos já identificados. Isso consiste num novo arranjo de gestão da notificação, constituindo uma inovação, uma vez que o MS define através da Portaria n. 936, a Rede de Prevenção da Violência e Promoção da Saúde e a Implantação e Implementação de seus Núcleos em Estados e Municípios (Brasil, 2004a). Nessa portaria é prevista a criação de um núcleo por município, mas na cidade do Rio a alternativa foi estimular a criação de 10 grupos articuladores um em cada CAP, ligados ao nível central.

A SMS/RJ sugeria à época a composição mínima dos grupos articuladores nas CAPs: um integrante da Divisão de Vigilância em Saúde (DVS), um profissional da Divisão de Administração e Planejamento em Saúde (DAPS) e um integrante do Serviço Social. Entretanto, esta composição pode variar de uma área para a outra, devido aos recursos humanos, à eleição de prioridades, à implicação e formação dos gestores e técnicos na área de violência, dentre outras razões.

O grupo articulador potencialmente poderá contribuir para a integração interinstitucional e intersetorial e, se necessário, solicitar apoio às áreas técnicas integrantes do NPSPV. A partir da análise do atendimento/notificação dos casos, incentivará e promoverá o desenvolvimento de atividades de prevenção da violência e promoção da saúde em seus territórios.

A CAP, portanto, tem um papel privilegiado na articulação da rede local no novo modelo de notificação e, consequentemente na utilização dos potenciais de recursos do território. Em relação às ações de enfrentamento da violência, o trabalho envolve, necessariamente, a articulação junto às unidades de saúde da rede municipal, com outras unidades não pertencentes à rede municipal (hospitais universitários e estaduais) e com a rede mais ampliada, sobretudo o CT, as escolas e os equipamentos da assistência social. Sabe-se que o trabalho em rede permite troca de informações, a articulação institucional e até mesmo a formulação de políticas públicas para implementação de projetos comuns, que colaboram para a integralidade da atenção, defesa, proteção e garantia de direitos das crianças, adolescentes e suas famílias em situação de violência (Souza et al., 2014). Todavia, exige uma série de requisitos difíceis de exercer, tais como conhecer os parceiros e reconhecer a importância de cada um; colaborar mutuamente; compartilhar saberes, ações, poderes, objetivos e projetos (Brasil, 2010).

\section{Potencialidades e dificuldades na implantação da ficha Sinan}

Todos os entrevistados apontaram o avanço na introdução de uma ficha padronizada para todo o território brasileiro, que permite o levantamento de informações regulares e a incorporação da questão da violência para vigilância em saúde, através de um sistema de informação.

A introdução da ficha Sinan permitiu retomar as discussões em torno da violência, além de incluir outros segmentos na notificação, especialmente as mulheres e idosos. Entretanto, alguns gestores e técnicos apontaram a necessidade de compreensão do fenômeno da violência numa perspectiva ampliada, para além dos limites do viés da vigilância epidemiológica, delimitada pela ficha Sinan.

O ponto negativo é aquele olhar da epidemiologia tradicional, da doença transmissível, que vocêfaz um bloqueio, que você tem procedimento muito claro, que você corta o círculo de transmissão da doença através do medicamento [...]. $\varepsilon$ a violência ela veio trazer outro paradigma de trabalho. Envolve trabalho de equipe, envolve um trabalho de tempo, envolve... a questão subjetiva. (Grupo Focal CAPs 3.1, 3.2, 3.3).

A fala acima corrobora definitivamente a incorporação de um novo paradigma de atenção às pessoas em situação de violência. É nesse contexto que o MS lança em 2010 a Linha de Cuidado para a Atenção Integral à Saúde de Crianças, Adolescentes e suas Famílias em situação de Violências. Este documento tem o propósito de sensibilizar e orientar os gestores e profissionais de saúde para uma ação contínua e permanente para a atenção integral à saúde de crianças, adolescentes e suas famílias em situação de violência (Brasil, 2010).

Como obstáculo, foi mencionado que a ficha é 
composta de muitos campos e variáveis, gerando certa resistência por parte dos profissionais.

$\varepsilon$ muito detalhada, as pessoas preenchem e sempre falta alguma coisa importante e a gente tem que envolver, pra corrigir novamente. Ou então, preenchem, mas não qualificam muito, tem campo para observações que a maioria das pessoas não preenche [...]. (Entrevistados CAP 5.1)

Segundo Njaine e Souza (2006), resistências do profissional de saúde à tarefa de preencher formulários que geram a informação ocorrem basicamente por duas razões: primeiro, por uma cultura que tradicionalmente desvaloriza o registro, e, em segundo, porque não há um retorno em termos de ações e medidas concretamente desencadeadas a partir da informação gerada (Njaine; Souza, 2006).

Outro obstáculo apontado reiteradamente por todos os profissionais e gestores entrevistados foi o medo de notificar casos de violência que envolvam crianças e adolescentes. Desde 1996 a notificação destes casos é adotada como diretriz no Município do Rio de Janeiro, todavia seguem tais resistências, atualizadas por relatos de experiências negativas não suficientemente relativizadas junto aos profissionais em face de outras práticas exitosas.

Nota-se que o medo de retaliações da família ou do autor da violência e o receio de envolvimento judicial incidem na subnotificação das situações de violência (Gonçalves; Ferreira, 2002). Outros fatores associados também têm sido identificados pela literatura: desconhecimento pelos profissionais de saúde da importância e dos usos da notificação (Patrício; Michaloski; Rujula, 2011); pouco apoio institucional para a realização da notificação (Silva; Ferriani, 2007); falta de formação ou capacitação do profissional para a identificação das situações de violência ou quanto aos procedimentos de notificação; descrença nos mecanismos sociais de proteção à criança (Saliba et al., 2007); e, até má compreensão do que sejam as orientações éticas profissionais quanto ao sigilo (Gonçalves; Ferreira, 2002).

Outra consideração crítica do processo se volta para o perigo do distanciamento e a fragmentação das ações entre as gerências responsáveis pela assistência e a vigilância, que sistematiza as in- formações. Observa-se que, com a entrada da SVS neste cenário, as gerências nem sempre participam da análise conjunta dos dados, podendo resultar na produção de informação que não retroalimenta ações efetivas de cuidado.

A minha preocupação é que em algumas situações isso ajuda a ficar a informação pela informação. [...] A gente vai se desobrigando num certo sentido quando o sistema de informação ele ganha robustez, mas em algumas situações ele distancia de quem está fazendo a gestão eu imagino que isso possa acontecer também no nível regional e no nível local. (Entrevistado $\mathrm{G}_{4}$ )

A fala demonstra que a própria gestão pode tratar a informação de forma burocrática, não a identificando como ferramenta para tomada de decisões. Portanto, a eficiência da notificação depende da contínua sensibilização dos profissionais/gestores para que reconheçam a importância dessa informação (Patrício; Michaloski; Rujula, 2011).

\section{Conclusão}

A implantação de uma ficha única em todo o território brasileiro pode ser considerada inquestionável avanço para a notificação e a criação de um sistema de informação sobre as situações de violência, especialmente de abuso sexual. A inclusão da notificação no campo da vigilância em saúde contribui para a capilarizar a notificação, qualificar e sistematizar registro, bem como permite potencialmente maior acessibilidade dos dados coletados.

O Brasil, comparado a outros países com mais tempo de implantação da notificação compulsória, como os EUA, apresenta a potencial vantagem de adotar um padrão nacional e padronizado de registro. Por outro lado, nos EUA, os registros de violência estão vinculados aos serviços de proteção à criança, o que pode facilitar o acesso à rede de apoio. Nesse sentido, grande parte dos investimentos norte-americanos é destinada à rede de serviços sociais, ao contrário do caso brasileiro. Um dos problemas estruturais que encontramos é a baixa integração da rede e a escassez de serviços especializados de atendimento (US, 2008a, 2008b, 2009; Ferreira; Souza, 2008). 
A SMS/RJ, ainda que de forma assistemática, vem promovendo treinamentos, grupos de trabalho e outras estratégias de sensibilização e que ganharam impulso com a implantação nacional do Sistema VIVA. No entanto, a descontinuidade das ações para o enfrentamento da violência é uma realidade constante (Paixão; Deslandes, 2011) e esta agenda é sacrificada a cada surto epidêmico.

$\mathrm{O}$ estudo mostrou que o trabalho em conjunto com as diversas instâncias do nível central possibilitou maior integração entre as ações. Portanto, a permanência e a adesão de outros parceiros estratégicos (interinstitucionais e intersetoriais) são fundamentais para continuidade do trabalho. A parceria com ONGs com expertise, universidades e centros de pesquisa que apoiaram as capacitações foi crucial na experiência carioca e pode contribuir no processo permanente de qualificação e avaliação das ações implementadas (Souza et al., 2014).

As CAPs podem ter um papel primordial nesse processo, a descentralização das ações e o fortalecimento da gestão local foram apontados como avanços. O desafio é o de se evitar a fragmentação das ações e a desarticulação das instituições que atuam nos casos de violência contra crianças e adolescentes.

Há a expectativa reiterada por estudos de que a incorporação recente dos profissionais da Estratégia de Saúde da Família contribua para o incremento da notificação e para ampliação das redes de apoio às crianças e adolescentes em situação de violência (Luna; Ferreira; Vieira, 2010).

Os obstáculos à implantação da ficha, como a resistência ao preenchimento de mais um instrumento com grande número de variáveis e o medo de notificar, podem ser diminuídos à medida que os profissionais tenham retorno das informações e dos dados coletados, permitindo o conhecimento da situação na sua esfera local. Além de ampliar as estratégias de institucionalização da notificação, bem como a sua divulgação (Souza et al., 2014; Brasil, 2013).

Consideramos que a incorporação de uma ficha padronizada de notificação das violências entre os agravos monitorados pelo Sinan é essencial para: dimensionar a demanda de casos destas formas de violência; identificar lesões de menor gravidade; conhecer a magnitude das violências e acidentes; tipificar as várias formas de violências; conhecer a violência "silenciada", principalmente a doméstica e sexual; caracterizar o perfil das vítimas e dos autores de violência. Espera-se que os dados produzidos a partir do Sinan possam integrar os dados dos diversos sistemas de informações, tanto da área de saúde como também da segurança, trânsito, dentre outros. Ferramentas tecnológicas como, por exemplo, o geoprocessamento, podem ser úteis para este fim. Esta ação é fundamental para o planejamento e organização das demais ações de promoção, prevenção e assistência, bem como para articular as forças sociais para intervenção em áreas e populações de maior risco social (Brasil, 2008).

Por fim, vale lembrar que a melhoria do sistema de notificação também tem o compromisso de instituir respostas mais efetivas de atenção e cuidado às vítimas e seus familiares. O preenchimento da ficha de notificação deve constituir o início de um fluxo de atenção às crianças e adolescentes, incorporando em caráter intersetorial as várias agências de proteção do Sistema de Garantia de Direitos, numa perspectiva de trabalho em rede (Veloso et al., 2013; Assis et al., 2012; Lima; Deslandes, 2011; Gonçalves; Ferreira, 2002; Brasil, 2002; OMS, 2002).

Entendemos que o investimento na cultura da informação e na qualificação da notificação são ações sinérgicas para o fortalecimento da rede de serviços. A ficha, portanto, mais que um instrumento burocrático, representa uma prática social de repúdio à invisibilidade e banalização da violência. Foi construída com a participação ativa de vários segmentos de defesa dos direitos de crianças, adolescentes e do movimento de mulheres e como tal agrega em torno de si a expectativa de instituir maior sinergia entre a possibilidade de melhor conhecer o fenômeno da violência e as respostas institucionais cabíveis.

Neste sentido, a ficha contribui para a consolidação da Rede de atenção integral às vítimas de violência, cabendo enfatizar a importância da articulação do Sistema de Saúde com a Rede de Atendimento e o Sistema de Garantia de Direitos, diante do desafio de identificar, notificar e encaminhar os casos, ampliando a resolutividade e garantindo proteção e defesa de direitos, especialmente nos grupos mais vulneráveis (Souza et al., 2014). 
Nota-se, portanto, que a experiência do Município do Rio de Janeiro no processo de implantação da ficha de notificação compulsória da violência preconizada pelo MS contribui para a reflexão deste processo nas grandes capitais brasileiras. Compreender as nuances do caso do Rio de Janeiro colabora para a identificação das dificuldades e das demais estratégias regionais adotadas.

\section{Referências}

ASSIS, S. G. et al. Notificações de violência doméstica, sexual e outras violências contra crianças no Brasil. Ciência \& Saúde Coletiva, Rio de Janeiro, v. 17, n. 2, p. 2305-2317, 2012.

BLEICHER, J. Hermenêutica contemporânea. Lisboa: Edições 70, 1980.

BRASIL. Portaria GM/MS n ${ }^{0} 737$, de 16 de maio de 2001. Diário Oficial da União, Brasília, DF, 18 maio 2001a. Seção 1E, p. 1-28.

BRASIL. Portaria MS/GM nº 1.968, de 25 de outubro de 2001. Diário Oficial da União, Brasília, DF, 26 out. 2001 b. Seção 1, p. 86.

BRASIL. Ministério da Saúde. Secretaria de Assistência à Saúde. Notificação de maus-tratos contra crianças e adolescentes pelos profissionais de saúde: um passo a mais para cidadania em saúde. Brasília, DF, 2002.

BRASIL. Portaria MS/GM nº 936, de 19 de maio de 2004. Diário Oficial da União, Brasília, DF, 20 maio 2004a. Seção 1, p. 37.

BRASIL. Secretaria Especial de Direitos Humanos. Ministério da Justiça. Estatuto da criança e do adolescente. Brasília, DF, 2004b.

BRASIL. Ministério da Saúde. Conselho Nacional de Secretários de Saúde. O desafio do enfrentamento da violência: situação atual, estratégias e propostas. Brasília, DF, 2008.

BRASIL. Ministério da Saúde. Departamento de Ações Programáticas e Estratégicas. Secretaria de Atenção à Saúde. Linha de cuidado para a atenção integral à saúde de crianças, adolescentes e suas famílias em situação de violências: orientação para gestores e profissionais de saúde. Brasília, DF, 2010.
BRASIL. Ministério da Saúde. Secretaria de Atenção à Saúde. Departamento de Ações Programáticas Estratégicas. Prevenção $e$ tratamento dos agravos resultantes da violência sexual contra mulheres e adolescentes: norma técnica. 3. ed. Brasília, DF, 2012.

BRASIL. Ministério da Saúde. Secretaria de Vigilância em Saúde. Departamento de Vigilância de Doenças e Agravos não Transmissíveis e Promoção da Saúde. Sistema de Vigilância de Violências e Acidentes (Viva): 2009, 2010 e 2011. Brasília, DF, 2013.

FERREIRA, A. L.; SOUZA, E. R. Análise de indicadores de avaliação do atendimento a crianças e adolescentes em situação de violência. Cadernos de Saúde Pública, Rio de Janeiro, v. 24, n. 1, p. 28-38, 2008.

FINKELHOR, D. Sexually victimized children. New York: Free Press, 1979.

GALDINO, A.; SANTANA, V. S.; FERRITE, S. Os centros de referência em saúde do trabalhador e a notificação de acidentes de trabalho no Brasil. Cadernos de Saúde Pública, Rio de Janeiro, v. 28, n. 1, p. 145-159, 2012.

GOMES, R. A análise de dados em pesquisa qualitativa. In: MINAYO, M. C. de S.; DESLANDES, S. (Org.). Pesquisa social: teoria, método e criatividade. Petrópolis: Vozes; 1994. p. 67-8o.

GONÇALVES, H. S.; FERREIRA, A. L. A notificação da violência intrafamiliar contra crianças e adolescentes por profissionais de saúde. Cadernos de Saúde Pública, Rio de Janeiro, v. 18, n. 1, p. 315319, 2002.

HABIGZANG, L. F. et al. Avaliação psicológica em casos de abuso sexual na infância e adolescência. Psicologia: Reflexão e Crítica, Porto Alegre, v. 21, n. 2, p. 338-344, 2008.

HARTZ, Z. M. A.; SILVA, L. M. V. Avaliação em saúde: dos modelos teóricos à prática na avaliação de programas e sistemas de saúde. Salvador: Universidade Federal da Bahia; Rio de Janeiro: Fiocruz, 2005. 
INSTITUTO PEREIRA PASSOS. Armazém de Dados. População residente, por idade e por grupos de idade, segundo as áreas de planejamento, regiões administrativas e bairros - 2000/2010 (Tabela: 2973). Rio de Janeiro, 2011. Disponível: <http://www.armazemdedados.rio. rj.gov.br/arquivos/2973_pop\%2opor\%2oidade\%20 e\%2opor\%2ogrupos\%2ode\%2oidade_ap_ra_ bairro_20oo_2010.ZIP>. Acesso em: 07 dez. 2011.

L'ABBATE, S. A análise institucional e a saúde coletiva. Ciência \& Saúde Coletiva, Rio de Janeiro, v. 8, n. 1, p. 265-274, 2003.

LIMA, J. S.; DESLANDES, S. F. A notificação compulsória do abuso sexual contra crianças e adolescentes: uma comparação entre os dispositivos americanos e brasileiros. Interface Comunicação, Saúde e Educação, Botucatu, v. 15, n. 38, p. 819-832, 2011.

LUNA, G. L. M.; FERREIRA, R. C.; VIEIRA, L. J. E. S. Notificação de maus-tratos em crianças e adolescentes por profissionais da Equipe Saúde da Família. Ciência \& Saúde Coletiva, Rio de Janeiro, v. 15, n. 2, p. 481-491, 2010.

MINAYO, M. C. de S. Violência e saúde. Rio de Janeiro: Fiocruz, 2006.

MINAYO, M. C. de S. O desafio do conhecimento: pesquisa qualitativa em saúde. São Paulo: Hucitec, 2008.

NJAINE, K.; SOUZA, E. R. Informação e comunicação sobre violência: instrumentos para a cidadania. In: MINAYO, M. C. de S.; SOUZA, E. R. (Org.). Violência sob o olhar da saúde: infrapolítica da contemporaneidade brasileira. Rio de Janeiro: Fiocruz, 2006. p. 269-282.

OMS - ORGANIZAÇÃO MUNDIAL DA SAÚDE. Relatório mundial sobre violência e saúde. Genebra, 2002.

PAIXÃO, A. C. W.; DESLANDES, S. F. Abuso sexual infanto juvenil: ações municipais da saúde para a garantia do atendimento. Ciência \& Saúde Coletiva, Rio de Janeiro, v. 16, n. 10, p. 4189-4198, 2011.
PATRÍCIO, K. P.; MICHALOSKI, L. C. R.; RUJULA, M. J. P. Vigilância em saúde. In: IBAÑEZ, N.; ELIAS, P. E. M.; SEIXAS, P. H. D. (Org.). Política e gestão pública em saúde. São Paulo: Hucitec: Cealag, 2011. p. 355-373.

SALIBA, O. et al. A responsabilidade do profissional de saúde sobre a notificação de casos de violência doméstica. Revista de Saúde Pública, São Paulo, v. 41, n. 3, p. 472-477, 2007.

SILVA, M. A. I.; FERRIANI, M. G. G. Violência doméstica: do visível ao invisível. Revista Latino Americana de Enfermagem, São Paulo, v. 15, n. 2, p. 275-281, 2007.

SOUZA, C. S. et al. Sistema de Vigilância de Violências e Acidentes/VIVA e a notificação da violência infanto-juvenil, no Sistema Único de Saúde/SUS de Feira de Santana-Bahia, Brasil. Ciência \& Saúde Coletiva, Rio de Janeiro, v. 19, n. 3, p. 773-784, 2014.

TEIXEIRA, M. G. et al. Seleção das doenças de notificação compulsória: critérios e recomendações para as três esferas de governo. Informe Epidemiológico do SUS, Brasília, DF, v. 7, n. 1, p. 7-28, 1998.

US - UNITED STATES. Department of Health and Human Services Administration for Children and Families Administration on Children, Youth and Families Children's Bureau. Child Welfare Information Gateway. Mandatory reporters of child abuse and neglect: summary of state laws. Washington, DC, 2008a.

US - UNITED STATES. Department of Health and Human Services Administration for Children and Families Administration on Children, Youth and Families Children's Bureau. Child Welfare Information Gateway. Establishment and maintenance of central registries for child abuse: summary of state laws. Washington, DC, 2008b.

US - UNITED STATES. Department of Health and Human Services Administration for Children and Families Administration on Children, Youth and Families Children's Bureau. Child Welfare Information Gateway. Making and screening reports of child abuse and neglect: summary of state laws. Washington, DC, 2009. 
VELOSO, M. M. X. et al. Notificação da violência como estratégia de vigilância em saúde: perfil de uma metrópole do Brasil. Ciência \& Saúde

Coletiva, Rio de Janeiro, v. 18, n. 5, p. 1263-1272, 2013.

VÍCTORA, C. G.; KNAUTH, D. R.; HASSEN, M. N.

Pesquisa qualitativa em saúde: uma introdução ao tema. Porto Alegre: Tomo Editorial, 2000.

\section{Contribuição dos autores}

As autoras trabalharam juntas em todas as etapas de produção do artigo.

Recebido: 17/07/2013

Reapresentado: 24/03/2014

Aprovado: 06/06/2014 